University of Wollongong

Research Online

Faculty of Commerce - Papers (Archive)

Faculty of Business and Law

January 2006

\title{
Getting in, getting on and getting out: reflections on a qualitative research project
}

H. J. Irvine

University of Wollongong, hirvine@uow.edu.au

M. Gaffikin

University of Wollongong, gaffikin@uow.edu.au

Follow this and additional works at: https://ro.uow.edu.au/commpapers

Part of the Business Commons, and the Social and Behavioral Sciences Commons

\section{Recommended Citation}

Irvine, H. J. and Gaffikin, M.: Getting in, getting on and getting out: reflections on a qualitative research project 2006.

https://ro.uow.edu.au/commpapers/119

Research Online is the open access institutional repository for the University of Wollongong. For further information contact the UOW Library: research-pubs@uow.edu.au 


\title{
Getting in, getting on and getting out: reflections on a qualitative research project
}

\begin{abstract}
Purpose. This paper seeks to provide a behind-the-scenes view of how a qualitative research project was conducted. It is therefore a paper about the process of qualitative research from the point of view of a researcher, rather than a qualitative research paper about an organization. Design/methodology/ approach. Its approach is both theoretical and reflective rather than being a description or analysis of what went on in the organization. Findings. Because the focus of the paper is personal rather than organizational, it does not offer "findings" about the way in which accounting is practised, but rather reflections and insights about the way research was conducted, from getting into the organization (getting in), conducting the research (getting on) and finally exiting the organization (getting out). Research limitations/implications. Even though this paper represents the reflections of one researcher conducting a qualitative study (and another coaching from the sidelines) in one unique organization, the experiences shared emphasize the need for flexibility, reflection and reflexivity in any qualitative research project. Practical implications. The intention of the authors is that this paper should be informative, but they do not view it as a manual of practice. It is hoped that it may help to prepare new researchers for what they may face as they conduct a qualitative research project, while at the same time providing resonances for experienced researchers. Originality/value. While much qualitative research has been undertaken within the discipline of accounting, little or no attention has been paid to the way in which that research has been conducted. This paper addresses that gap, in the hope that it will enlighten both experienced and new qualitative researchers.

Keywords

case studies, qualitative research, ethnography, theory in qualitative research

Disciplines

Business | Social and Behavioral Sciences

\section{Publication Details}

This article was originally published as Irvine, $\mathrm{HJ}$ and Gaffikin, $\mathrm{M}$, Accounting, Auditing \& Accountability Journal, 19(1), 2006, 115-145. Copyright Emerald. Original journal available here.
\end{abstract}




\title{
Getting in, getting on and getting out: reflections on a qualitative research project.
}

\author{
Helen Irvine* \\ and \\ Michael Gaffikin**
}

* Helen Irvine, the corresponding author, is a Senior Lecturer in Accounting in the School of Accounting \& Finance at the University of Wollongong.

$\begin{array}{ll}\text { Email: } & \text { hirvine@uow.edu.au } \\ \text { Address: } & \begin{array}{l}\text { School of Accounting \& Finance } \\ \text { University of Wollongong }\end{array} \\ & \begin{array}{l}\text { Northfields Avenue Wollongong NSW Australia } 2522 \\ \text { Telephone: }\end{array} \\ +61242215919 \\ \text { Fax } & +61242214297\end{array}$

** Michael Gaffikin is Associate Dean (Research) in the Commerce Faculty of the University of Wollongong.

$\begin{array}{ll}\text { Email: } & \text { gaffikin@uow.edu.au } \\ \text { Address: } & \text { Commerce Faculty } \\ & \text { University of Wollongong } \\ & \text { Northfields Avenue Wollongong NSW Australia } 2522 \\ \text { Telephone: } & +61242213380 \\ \text { Fax: } & +61242214157\end{array}$

Acknowledgment: The authors wish to acknowledge the helpfulness and willing co-operation of the members of Hearts and Hands, both ordained and employees, during the course of this study. Thanks are also due to the editors and anonymous reviewers of this paper for their helpful comments and encouragement. 


\title{
Getting in, getting on and getting out: reflections on a qualitative research project.
}

Keywords: case studies in accounting; qualitative research; ethnography; theory in qualitative research.

\begin{abstract}
This paper provides a behind-the-scenes view of how a qualitative research project was conducted. It is therefore a paper about the process of qualitative research from the point of view of a researcher, rather than a qualitative research paper about an organization. Its approach is both theoretical and reflective rather than being a description or analysis of what went on in the organization. Because the focus of the paper is personal rather than organizational, it does not offer "findings" about the way in which accounting is practised, but rather reflections and insights about the way research was conducted, from getting into the organization (getting in), conducting the research (getting on) and finally exiting the organization (getting out). Even though this paper represents the reflections of one researcher conducting a qualitative study (and another coaching from the sidelines) in one unique organization, the experiences shared emphasize the need for flexibility, reflection and reflexivity in any qualitative research project. The intention of the authors is that this paper should be informative, but they do not view it as a manual of practice. It is hoped that it may help to prepare new researchers for what they may face as they conduct a qualitative research project, while at the same time providing resonances for experienced researchers. While much qualitative research has been undertaken within the discipline of accounting, little or no attention has been paid to the way in which that research has been conducted. This paper addresses that gap, in the hope that it will enlighten both experienced and new qualitative researchers.
\end{abstract}


Few qualitative researchers have described in detail the ethical and political processes of 'getting in, getting on and getting out' of their research settings (Darlington and Scott, 2002, p. 31)

\section{Introduction}

In recent years, there has been a dramatic increase in case studies in the accounting and management literature (Parker and Roffey, 1997, p. 242; Humphrey and Scapens, 1996, p. 87), and it has been suggested that more are needed, in order to capture "the dynamic and contextual complexity of 'living' organizations" (Feeney, 1997, p. 506). However, while there have been many calls for qualitative accounting research, there has been little explicit attention given to the dynamics of such work [1], with publications required to strike a somewhat unsatisfactory compromise between methodology, case data and interpretation. The result is that personal and anecdotal accounts are "not widely written of" (Punch, 1998, p. 160).

A recent penetrating study of accounting's role in management-labour relations (Ezzamel et al, 2004), for example, provides only a few details of the way data were collected and interpreted. Given the dense nature of the research, this is quite an appropriate weighting to the method of conducting the research, but illustrates the difficulty, when writing about a qualitative research project, of finding a balance between explaining (and defending!) the way the qualitative research was conducted, and actually reporting the insights gained from the study. It also illustrates the reality that most qualitative research literature gives other accounting researchers no indication of what goes on behind the scenes within an organization, or of the difficulties that qualitative researchers inevitably face:

all research conducted in organizations will present some difficulties as organizations are complex and dynamic sociopolitical worlds ... feedback loops from the research to policy and practice will often be central to the 
research, and the tensions which may arise need to be anticipated and managed in an honest and open manner (Darlington and Scott, 2002, pp. 33, $34)$.

Qualitative research is messy, and it never goes according to plan, as researchers become aware of the political and ethical "perils" and "pitfalls" of actually carrying out research (Punch, 1998, p. 159). In spite of this, or perhaps because of it, there are not many accounts of qualitative research that touch on "the stress, the deep personal involvement, the role conflicts, the physical and mental effort, the drudgery and discomfort - and even the danger - of observational studies for the researcher" (Punch, 1998, p. 160). Usually by the time qualitative accounts reach academic journals they have been sanitized.

This paper redresses this silence by providing a first-hand account of a qualitative research project in accounting, but with a focus on the way in which the study was conducted, rather than on the actual case data. The normal order in which qualitative research is reported will therefore be reversed, with the case study data taking second place behind the actual dynamics of the project. Academic literature provides the backdrop against which reflections are provided. These reflections (in italics) are purposeful, not only telling the story of the project, but also revealing the intensely personal and reflexive nature of qualitative research. While they are the primary author's reflections, they are also the secondary author's, who, as the supervisor of the project, coached the primary author from the sidelines.

The next section will provide background of some of the main issues of qualitative research and a brief introduction to the organization in which the study was conducted. Case information will be minimal, offering mere glimpses of the context and culture of the research site, and of the research issues considered, 
rather than in-depth and extensive information. The three sections following reinforce the people-oriented nature of qualitative research, being written from the point of view of the (primary) author's interactions with people in the organization in the process of getting into the organization, getting on with the research, and getting out at the end of the project, i.e. in negotiating and conducting relationships through the various stages of the research from initial access issues to the completion of a final report. Concluding comments reinforce the messiness, unpredictability and unique nature of every qualitative research site and urge researchers to overcome their apprehension about "exposing their decisions 'warts and all' and leaving themselves open to criticism" (Darlington and Scott, 2002, p. 34).

\section{Setting the scene.}

\section{Qualitative research issues.}

Qualitative research acknowledges the contextual nature of inquiry (Glesne and Peshkin, 1992, p. 7). It has been described as "watching people in their own territory ... interacting with them in their own language, on their own terms" (Kirk and Miller, 1986, p. 9). Its intellectual roots go back well over a hundred years to the birth of social science itself (Tesch, 1990, p. 9), and it is currently identified as a successful and popular form of contemporary social research in the fields of sociology, cultural anthropology, political science, and other disciplines, including education, nursing, social work (Atkinson, 1995, p. 117), and, increasingly, accounting. It enables researchers to "get close" to participants, to "penetrate their internal logic and interpret their subjective understanding of reality" (Shaw, 1999, p. 60), to aid in the understanding of the way institutions evolve (Mouck, 1998, p. 
58 ), to display the interplay between accounting and organizations' "cultural and technical systems" (Dent, 1991, p. 707), and to understand better how accounting meanings are "socially generated and sustained", allowing research questions to be generated out of actual cases, rather than being imposed upon them (Hopper and Powell, 1985, p. 447).

Distinguished from quantitative research [2], with its reliance on the power of numbers, the aim of qualitative research is a "quest for meaning and significance" (Marshall et al, 1991, p. 74). It involves acknowledging the impossibility of representing the complexity of social reality with just one data set (Covaleski and Dirsmith, 1990, p. 544) and attempting to understand this complexity, analysing and interpreting data from various sources. Qualitative researchers emphasize the "value-laden nature of inquiry", and seek answers to questions that stress the meaning of social experience, in contrast to quantitative research, which emphasizes "measurement and analysis of causal relationships between variables", supposedly within a "value-free framework" (Denzin and Lincoln, 2003, p. 13). Young and Preston (1996) suggested that the reason there were so few explanatory case studies in accounting was twofold: there were structural barriers to entry within the academic accounting literature, and there were very few scholarly, explanatory accounting case studies. They contrasted the "inherently messy, contradictory and unwieldy" nature of case study research with the "technique-laden, highly structured and devoid of interpretation" case studies which had been presented in the accounting research literature (Young and Preston, 1996, p. 110). 
Actually undertaking a qualitative research project [3] depends on the conviction of the researcher, the nature of the problem to be investigated, the desire to gain a "fresh slant" on things, and the commitment to give "intricate details of phenomena that are difficult to convey with quantitative methods" (Strauss and Corbin, 1990, p. 19). Since its focus is on "naturalistic", "ethnographic", and "participatory" forms of research (Kirk and Miller, 1986, p. 9), a qualitative researcher is usually a person who does not find quantitative methods appealing, who has a high tolerance for ambiguity, and who is prepared to invest time in research which demands a continual interaction [4] between the dimensions of reading, reflection, and data gathering (Glesne and Peshkin, 1992, p. xiii).

My priority was to focus on the "human" side of accounting, to attempt to understand the complex interrelationships between an accounting system and the people who designed it, created it, and used it.

Ethnography, "a description of the folk", is both a process (i.e. a research technique) and a product (Boyle, 1994, p. 161). Central to ethnography is the idea of extended participant observation (Sanday, 1979, p. 527), which involves an attempt, on the part of a researcher, to understand what it is like for people in a particular situation. Uppermost in the enthnographer's mind is the acknowledgment that

social systems are not natural phenomena, they cannot be understood independently of human beings and the researcher cannot be regarded as a neutral independent observer. The social reality must be interpreted by the researcher and, thus, case studies represent interpretations of the social reality (Ryan et al, 2002, p. 159).

Data, different from that accumulated for quantitative research, are gathered during the process of fieldwork. It consists of in-depth, open-ended interviews, direct observation, written documents (Strauss and Corbin, 1990, p. 20; Patton, 2002, p. 10), and "any information the researcher gathers that is not expressed in 
numbers" (Tesch, 1990, p. 55). An ethnographic project demands "complete commitment to the task of understanding" (Sanday, 1979, p. 527). It can be conceived, from an anthropological viewpoint (which is where ethnography originated) as

... a written description of a people that focuses on selected aspects of how they lead their routine, remarkable, and ritual lives with each other in their environment, and of the beliefs and customs that comprise their common sense about their world (Muecke, 1994, pp. 189 - 190).

The term "fieldwork" describes the way ethnography is undertaken. Reasons for choosing an ethnographic form of research include recognizing the need for an empirical approach, the need to remain open to the unexpected, and a desire to ground observations "in the field". The concern is with how the "cultural whole" is depicted (Baszanger and Dodier, 1997, pp. 10 - 11). In spite of this, ethnography is by no means "a coherent, unified and monolithic research genre" (Jönsson and Macintosh, 1997, p. 371). It is instead a research tradition with several different aims and foci [5]. Traditionally, ethnography has been based on the process (participant observation) of ethnographic naturalism, and the product of "ethnographic realism" (Schwandt, 1997, p. 42). Differences between types of ethnographies reflect differences in theoretical or epistemological positions (Atkinson and Hammersley, 1994, p. 257), and these come into play not only in the production of an ethnographic text, but also in the very conception and design of the research project, the formation of issues to be investigated, the way that investigation is undertaken, and the role that theory plays, whether it is simply a means of making sense of observed data, or a call to action to rectify perceived injustices: 
The gendered, multiculturally situated researcher approaches the world with a set of ideas, a framework (theory, ontology) that specifies a set of questions (epistemology) that are then examined (methodology, analysis) in specific ways (Denzin and Lincoln, 1998, p. 23).

If a researcher acknowledges that social systems are socially constructed, and therefore, "can be changed by the activities of individuals located within a specific social context" (Ryan et al, 2002, p. 126), then that researcher must also see himself or herself as "the instrument of their own research", acknowledging that "the interpersonal relationships and dynamics which can emerge are complex and deeply charged for both the researcher and the researched" (Darlington and Scott, 2002, p. 46). This ontology requires ethnographers to go beyond the production of narratives about the people being studied, and to include "insights into the way these subjectivities come to be constituted" (Jönsson and Macintosh, 1997, p. 383).

There is thus wide scope within the "complex historical field" of qualitative research for different theoretical paradigms (Denzin and Lincoln, 1998, p. 2), yet while there are different types of ethnographies (Muecke, 1994; Jönsson and Macintosh, 1997), they all have certain hallmark characteristics. First, ethnographies are holistic and contextual (Boyle, 1994, p. 162). Describing behaviour is not sufficient for the ethnographer, who wants to understand the context of that behaviour [6]. With this goal, fieldwork is essential, because it is through fieldwork that the ethnographer gains the understanding which is the object of the study (Schwandt, 1997, p. 44). Fieldwork must involve a concerted effort to work with people over a long period of time, in order to come to a "rounded" understanding of the different interrelationships between people who 
work among the systems and subsystems of a particular social context (Boyle, 1994, p. 163).

These systems are conceived in people's minds, but gain substance and tangibility in the design of forms, accounts, manuals, operating procedures, committees and documents. Since qualitative research is people-oriented, the significance of systems can be described as the way people have determined that information will be shared within the organization, i.e. in the design of documents, the conduct of meetings, the choice of people who attend meetings etc. A survey alone could not possibly lead to this type of understanding. Empathy is a natural and necessary part of this process (Baszanger and Dodier, 1997, p. 12), so that techniques for the analysis of the data gathered in this way are not as important as the nature of the data itself. Whether the data are treated in a quantitative manner, or whether they are analyzed manually or by computer, is immaterial. What needs to be acknowledged is that data reflect multiple realities, and it could be used to produce a number of different "stories" of the organization.

Secondly, ethnographies involve a reflexive process, since the ethnographer becomes part of the world that is being studied, and, therefore, cannot avoid being affected by it. The ethnographer is not just an academic researcher, not just a "remote, objective towering figure of authority deigning to move away from professorial grandeur in the academy briefly to rub shoulders with the grubby inhabitants of the world of factories and commerce" (Watson, 1995, p. 309). Finding the "right distance" between him/herself and the group being studied is thus a dilemma for the ethnographer (Baszanger and Dodier, 1997, p. 12), and involves conscious work. 
Thirdly, whatever that "right distance" is, the reflexivity inherent in ethnography produces a combination of the "insider" (emic) and "outsider" (etic) views, a dimension which "rounds out the ethnographic picture", and assists the researcher to interpret what is going on (Boyle, 1994, p. 166). The role of theory in this reflexive process may vary, depending on the researcher's particular emphasis.

Fourthly, ethnography is a product [7]. While not necessarily conforming exactly to anthropological traditions, it is enriched by anthropological notions of culture and data collection and analysis. Whether it should have a transformative aim is a huge issue for some researchers, and has implications for notions of confidentiality which, if not challenged, actually protect undesirable practices, or power relationships. Some researchers believe strongly that these ought to be exposed (Baez, 2002).

An ethnography is therefore a study of human activities with an empirical approach, open to observation, and grounded in a specific context (Baszanger and Dodier, 1997, p. 19). It incorporates a strong emphasis on exploring the nature of particular social phenomena, rather than setting out to test hypotheses about them; it illustrates a tendency to work primarily with unstructured data; it investigates a small number of cases, usually one, in detail; and in the analysis of ethnographic data, the emphasis is on interpretations of meanings, in the form of verbal descriptions, with quantification and statistical analysis playing "a subordinate role at most" (Atkinson and Hammersley, 1994, p. 248).

\section{Hearts and Hands.}

The ethnographic study on which this paper is based was conducted as part of a doctoral project. It was a year-long study of accounting in an Australian division 
of an international religious/charitable organization, Hearts and Hands [8]. In keeping with much qualitative research, where "developing the embryonic question into a researchable form is more difficult and ... the question(s) may continue to be refined throughout the whole study" (Darlington and Scott, 2002, p. 18), the research question evolved over time. Initially conceived as an investigation of Hearts and Hands' budgeting processes, its focus shifted to include the impact of the adoption of accrual accounting and corporate-style financial reporting on organizational structures and personnel. In conducting an explanatory case study [9], the authors' aim was to "attempt to explain the reasons for observed accounting practices", the development of theory, therefore, representing an attempt to provide a "convincing" explanation of actual observed practices (Ryan et al, 2002, p. 144). The theoretical lens employed was that of institutional theory, informed by resource dependence theory.

Hearts and Hands enjoys high status in Australia, and has a reputation to uphold. Issues of confidentiality, particularly in relation to financial matters, were therefore of paramount importance to members of the hierarchy, and employees interviewed were extremely conscious of the need to maintain that reputation, since the organization relied heavily on the goodwill of the public in terms of donations and other forms of assistance. The unique history and culture of the organization also played a vital role in the conduct of the research project. The organizational structure was extremely authoritarian and hierarchical, with subjects who were interviewed working in a variety of roles, from local churches to aged care facilities and drug rehabilitation centres. The hierarchy worked not only through the organization's official structure, but also in making a distinction between ordained members (who invariably filled the posts at the top of the 
organizational hierarchy) and employees, some of whom shared the organization's religious beliefs and were members themselves, and others who had no affiliation with the organization except as employees.

At the time of the study, the environment in which Hearts \& Hands operated was changing significantly. More stringent accountability and reporting requirements linked with government funding, together with cutbacks in that funding and pressure to increase corporate donations catapulted the organization into a new level of professionalism. The introduction of accrual accounting to Hearts \& Hands, a consequence of this changing environment, was a huge issue for staff, both ordained and non-ordained. Many of those ordained were not qualified in accounting, even though they carried significant financial responsibilities. The increase in sophistication of the accounting system necessitated the employment of more qualified professionals, which exacerbated existing lines of demarcation and heightened the frustrations from both groups. Issues of researcher personality, geographical dynamics (the subjects interviewed were from widely disparate and diverse geographical areas), the culture of the organization itself, the fact that it was an academic study, the sensitivity of organizational gatekeepers to the slightest possibility of negative publicity, the production of a final report and the ongoing social and moral obligations of the researcher were all significant issues in the conduct of the research (Punch, 1998, pp. 162 - 166). From a research perspective, these factors made an interesting site highly political and sensitive, as will become obvious in the discussion which follows.

During an access period, researchers are able to observe the mobilisation of many of their studied beliefs about qualitative research as naturalistic inquiry, as they 
gather qualitative data, attempt to understand the accounting system as part of the whole organization, use inductive analysis from this holistic perspective, depend on the goodwill of others through personal contact and insight, observe the dynamic nature of the organization and its constantly shifting power blocs, become aware of the impact of sensitive contextual issues, appreciate the need for empathic neutrality and experience the necessity of taking a flexible attitude towards research design over the year of access (Patton, 2002, pp. $40-41$ ). The next three sections, "Getting in", "Getting on" and "Getting out”, provide a record of some of these experiences.

\section{Getting in.}

\section{Choosing a research site.}

Qualitative research both requires and provides great flexibility in approach [10], and a huge investment of time. By the time a researcher has gained access to an organization and has designed a project, a considerable amount of time has already been invested in the research, and from that point onwards, it would be difficult to abandon the activity. Making a wise choice of a research site is therefore vitally important.

The organization chosen is capable of having a strong influence on the nature of the qualitative research undertaken, so the purpose of that research needs to be considered [11]. Qualitative research has the potential not only to generate "new knowledge", but also to "inform critically public policies, existent social movements, and daily community life" (Fine and Weis, 1996, pp. 264 - 265). A research site ought to be chosen which offers scope not only for the collection of rich data, but also flexibility about a research topic, and the potential at least to 
think radically (Schwandt, 1997, p. xxi) about what is going on within the chosen organization.

Two more factors that strongly influence the choice of site are the area of inquiry the researcher initially finds appealing, and the possibility of gaining access. The concepts that inform early impressions and opinions of what constitutes a potential research area will probably emanate from previous research, or from current theoretical reading about issues that are believed to be significant. Alternatively, a research site might be chosen because of its very ordinariness, not because it is unusual or significant, but because it is typical, or undistinguished (Ragin, 1994, p. 85, p. 87). While ease of access will probably not be the only consideration in choosing a research site, having a contact within a particular organization could be a deciding factor.

Hearts \& Hands was an interesting potential research site due to its unique history and culture, the fact that it was a religious organization, involved in charitable work, with a high profile in the Australian community. A colleague told me that he could introduce me to somebody he knew who worked in the organization. From this "second-hand" contact, the process of gaining access began. I was about to throw my lot in with Hearts \& Hands.

\section{Gaining access.}

Why would an organization grant access to a researcher? Why would any organization allow an academic (or anybody else) to observe their innermost secrets, their ways of doing things, their mistakes, and their problems? Scott (1965, p. 275) [12] suggested that reasons varied widely, from altruism to selfinterest. It would be expected that there would be at least some resistance to an approach for the kind of access required in order to conduct qualitative research, simply because very few organizations would be willing to be completely open. 
The issue for a researcher when faced with the need to gain access is, how is this to be achieved with minimum inconvenience and maximum benefit? It needs to be done ethically correctly [13] (Glesne and Peshkin, 1992, pp. 111 - 112), it needs to be done wisely, and it needs to be done in a way that will ensure, or at least open up the possibility of, flexibility in the matter of the research question.

Contacts within the organization will obviously be of great assistance [14], but even if they are not in a position to grant access, they may at the very least be able to advise the correct protocol for requesting access, and the people of whom such a request would need to be made. It is essential to identify the "gatekeepers" of an organization, bearing in mind that it could be risky to start anywhere but at the top (Glesne and Peshkin, 1992, p. 35). Once the gate to access has been shut at a lower level, it is then difficult to have it re-opened later.

Negotiating an access agreement is crucial to the success of the project. There will be many issues arising during the course of a qualitative research project which may be unanticipated, and which, if the ground rules for the relationship have not been wisely laid down, could cause the study to founder. It needs to be made quite clear, from the outset, that qualitative research is flexible, that its practical value to the organization may not be as obvious as they would hope, and that any obligations which are agreed to must be agreed to within these contexts:

in general, the researcher should realize that most organizational officials will have at best a vague notion of what social researchers do or how they do it, and many officials will be inclined to overestimate the practical value of the research results. Researchers must attempt to set realistic limits on these expectations (Scott, 1965, p. 276).

A powerful motivator for organizations in granting access for a particular study is the possibility that they might gain some benefit from it (Scott, 1965, p. 275). 
Expectations and obligations need to be itemized as carefully as possible at the time when access is being negotiated if ethical behaviour is to be achieved throughout the research project. There will undoubtedly be various ethical dilemmas that a researcher will face during this period of negotiation and later during the access period itself. In the stress of negotiating access, it would be easy to avoid confrontation or commitment, only to find later that unresolved issues might hinder or even jeopardize the continuation of the research project.

It must be understood that the relationship between the researcher and organizational members will change during the course of the research process. This is inevitable. Initially, when access is being arranged, the researcher and organizational gatekeepers have a one-sided relationship based on their situation rather than any knowledge they have of each other. In most cases, they really do not know each other at all. The researcher, in spite of any background knowledge of the organization, knows about it only as an outsider. The organizational members responsible for negotiating the access agreement, unless they have been academics themselves, are likely to have a limited understanding of how fuzzy the academic research process can be. The nearest experience they will have had will be probably through consultancies that may have been conducted in the organization.

Initially at least, in the desire to gain access, the hopeful researcher may be eager to please, keen to convince, and willing to compromise. The gatekeepers, in contrast, are in a strong bargaining position. They are able to make demands, however onerous. Once access is achieved, however, this relationship may shift. After a period of time, it may be that the researcher gains knowledge that those 
gatekeepers do not have, that the organization becomes an exploiter of the researcher's time and energy, or that the researcher attempts to exploit the organization. Depending on the level of involvement, the researcher may be tempted to intervene in organizational policy, or to speak up for some member whose case has perhaps not been heard, or has been misunderstood. The role of the researcher, once access has been gained, can be ambiguous. Is the researcher simply an observer, or an exploiter, an intervener, a reformer, an advocate, an advisor, or a friend (Glesne and Peshkin, 1992, pp. 111 - 112)?

\section{The negotiation process.}

My Hearts \& Hands contact was Henry Johnson [15]. Before meeting him, my preparation included a study of the organization's community social work and its associated budget, issues relating to government funding and accountability, and consideration of the type of access I would be aiming for. Henry offered to speak to his Area Superintendent on my behalf, and to forward a letter of introduction from the university. He informed me later that the Area Superintendent wanted me to send a letter outlining what my research would involve. Based on the preliminary research I had done, the way in which the budget contributed towards the fulfilling of Hearts and Hands' mission was my primary interest. The construction of a suitable letter was a time consuming exercise. Given that the Area Superintendent was near the top of the hierarchy, but not quite at the very top, the wording had to be just right. I asked for an interview, because what I did not want at this point was for the organization to be closed to me, especially since I was convinced it would be a rich and fascinating study site. Eventually the Area Superintendent's secretary telephoned me and we set an appointment time.

On the eve of the interview, I received an unexpected call from Hearts \& Hands' Divisional Deputy Chief Financial Officer (Deputy CFO) in Sydney. The Area Superintendent had forwarded my letter on to him, and he and the CFO were both interested in meeting with me. As a result, my interview with the Area Superintendent was therefore less significant in terms of access. Friendly and interesting, it helped me to prepare for the important interview later in the day.

At Hearts \& Hands' head office, I was issued with a visitor's badge, and ushered into the board room on the $10^{\text {th }}$ floor. The CFO seemed slightly nervous about the project, since their budgeting system wasn't "that great", and they might be embarrassed about what I might find. Two issues were of paramount importance to him: confidentiality and the benefit Hearts \& Hands might gain from the study.

His concern about confidentiality issues hinged on the need to protect Hearts \& Hands' image. The use of the organization's name was problematic. The CFO 
asked who would read the thesis, and whether it was to be published. I explained the existence of dissertation databases, and the accessibility of theses. He wanted privacy for the interviewees, acknowledging that sometimes people would want to be assured of this before they offered any response to questions. In order for Hearts \& Hands to benefit from the study, I was asked to present a written report, and to deliver my "findings" at a conference for executive staff, which was held annually. He did not want a report that simply gathered dust on a shelf, but one that would be discussed and have an impact on the organization's practice.

He asked me to submit a plan of action, indicating my proposed time-frame, goals, a description of how the study might benefit them, and an estimation of the number of people I anticipated interviewing at each level of the organization. He would then submit the proposal to Hearts \& Hands' Finance Council, the organization's top financial policy-making body. I agreed, pointing out that it was difficult to specify in advance exactly what direction the research might take.

\section{The access agreement.}

The construction of my research proposal was a demanding task, given the multiarea, hierarchical structure of the organization. After receiving some advice and feedback from colleagues, I completed the final document and posted it, aware that if this failed, to have to attempt to gain access to another organization at this stage would have been extremely demoralizing.

After hearing nothing for four weeks, I telephoned the CFO. He was not happy with the two-year time frame I had proposed, and suggested that I should begin the project immediately, which would enable me to observe the entire budget cycle, and present my report to the executive staff in October of the following year. It was September at the time. I assured him that I was very keen to begin, and agreed to make the changes immediately. While I spoke positively and confidently, the prospect of bringing the whole project forward like this was a shock, since I would not be able to complete the background research I had planned. By the end of the day I had posted my revised proposal. The waiting game continued.

After one week I met again with the CFO and the Deputy CFO at Head Office. The CFO conducted the meeting, and focused immediately on what he saw as the central issues of the project. Attendance at Budget Committee meetings was not a problem. The use of the name, however, was once again problematic. He preferred to reserve his decision on that matter until I had presented my report to Hearts \& Hands [16].

The CFO required all interviews to be recorded to ensure their accuracy, and further, that they be transcribed and offered to all interviewees to be signed as a correct record of the conversation. After some discussion, it was decided that I would be based in the Accounting Department with my own desk, with the Deputy CFO, who headed that department, as a contact person. He said, somewhat apologetically, that his major concern was that Hearts \& Hands should benefit from the study, and if this were to occur, he would willingly have me there five days a week. If it were just for my own personal study, however, one day a week 
would be quite sufficient. I said I understood his concern, and reiterated my earlier comment that while this would not be primarily a management consulting exercise, there would be insights for them.

The CFO and Deputy CFO seemed satisfied with all that we had discussed, and we set some dates on which I would visit Head Office. I explained that after an initial period at Head Office, I intended moving out to the areas, concentrating on the Central Area, but visiting some of the others as well. The CFO agreed that this was a good idea, since Central Area was their largest section, with the most diversity. The meeting ended on a friendly note. It had taken two months from the time of my first contact to work out the access arrangements, but eventually I had a "yes".

\section{Getting on.}

\section{Preparations.}

I had two weeks in which to absorb the conditions of access before I began at Head Office. Several issues seemed significant or onerous to me: transcribing all the interviews and getting a grasp of the way the organization worked. It had been obvious in my initial contacts with ordained staff, that they had no difficulty in talking about money. Another initial impression was that Hearts \& Hands, as an organization, was extremely hierarchical. Several had already mentioned that feature of their organization to me, spontaneously, as an almost humorous observation of the way they were.

\section{Data gathering.}

Scott (1965, p. 265) observed that there are many approaches to field research and it is partly the nature of the phenomena being investigated and the objectives of the study which must determine "what approaches are taken and what materials are gathered by what methods"[17]. To these must be added the researcher's own philosophical beliefs, since before anything is observed in an organization, the researcher has already formed opinions about what constitutes reality, what is worthy of study, and what is an appropriate means of conducting that study.

If the aim of social science is to produce descriptions of a social world, then those descriptions ought to correspond in some way to that particular social world (Peräkylä, 1997, p. 201). The way such descriptions will achieve that aim is if they are based on interactions and observations of the way people actually act and 
relate. A qualitative researcher therefore gathers a variety of types of data, all of which contribute to this understanding. Data gathered from interviews, observations, fieldnotes, and a study of documents, when combined, will form the reservoir of materials on which the qualitative researcher will base his or her descriptions and analysis of a given social situation [18]. As the data is absorbed, the researcher's initial area of interest may change and develop into something quite different [19]. This provides exciting possibilities.

Budgeting was my initial interest at Hearts \& Hands. The way an organization allocates its resources was especially interesting in a religious organization, which had a spiritual agenda rather than an overtly financial one. My initial contact with the Accounting Department, including conversations, observations, the study of Budget Committee minutes, and early interviews, quickly reinforced my belief that budgeting was not an isolated process. It was deeply embedded in Hearts \& Hands' culture and mission, the personalities and expertise of those involved, the hierarchical, autocratic structure, and the constant pressure of funding limitations. My research interests developed and changed as I was confronted by the data and reflected upon it.

\section{Interviews.}

Interviews offer a unique opportunity to explore the points of view of others, entering, at least in understanding, into their social world (Miller and Glassner, 1997, p. 100). The manner in which they are conducted is vital if this understanding is the aim:

I realized quite early in this adventure that interviews, conventionally conducted, were meaningless. Conditioned cliches were certain to come. The question-and-answer technique may be of some value in determining favored detergents, toothpaste and deodorants, but not in the discovery of men and women (Douglas, 1985, p. 7).

This statement acknowledges that some interviews reveal very little about people, because of the manner in which they are conducted. An experienced researcher recognizes that interviews are "interventions", affecting people, and that a "good" 
interview "lays open thoughts, feelings, knowledge, and experience not only to the interviewer but also the interviewee" (Patton, 2002, p. 353). It is not cliched responses to set questions that help the qualitative researcher gain understanding, but rather the possibility of both letting people "offer their interpretations of reality" and allowing the researcher freedom "to move in any direction that appears interesting and rich in data" (Tierney, 1991, p. 9). Structured interviews, where the content and order of questions are specified in advance, are therefore of limited value, but semi-structured, unstructured (Walizer and Wienir, 1978, p. 288), or "creative" interviews (Douglas, 1985) offer much greater opportunities to tap into realities "beyond the interview context" (Miller and Glassner, 1997, p. 102) [20]. Interviewing challenges include "unexpected participant behaviours, dealing with the consequences of the interviewers' own actions and subjectivities, constructing and delivering questions, and handling sensitive research topics" (Roulston et al, 2003, p. 643).

The issue of how to conduct interviews, i.e. interviewing style, is therefore not simply a technical one, but rather a theoretical one, being determined by the researcher's understanding of the nature of qualitative inquiry and its purposes and intentions [21]. Once the type of interview is determined, based on theoretical considerations, then technical aspects of interviewing can be considered. These occupy a great deal of the researcher's time and energy. Choosing whom to interview, making contact, setting up appointments, deciding whether or not to tape-record, typing transcripts, taking notes, learning to listen, developing questions, learning to deal with the unexpected, establishing rapport, knowing how many interviews are enough, and attention to dress and body language, are all important issues for the interviewer (Tierney, 1991; Douglas, 1985; Glesne and 
Peshkin, 1992; Fontana and Frey, 1994; Altheide and Johnson, 1994).

Interviewing, or "asking questions and getting answers" is a much more difficult

task than it may seem at first [22] (Fontana and Frey, 1994, p. 361).

In interviewing, I usually found no difficulty in getting people to talk. The issue was rather, moving from the "warming up" phase of the interview to the serious business of the interview, which I expected would provide "good data" as well as "good conversation". Since all interviews had to be transcribed, the challenge was to keep them short without sacrificing rapport-building conversation.

Over time, I developed several "banks" of possible questions based around six areas of interest: the mission of the organization, the interviewee's personal background, organizational structure, money and fundraising, accounting and budgeting, personnel issues and the future of Hearts \& Hands as they perceived it. Pre-interview research often alerted me to issues that might be significant, and as much as possible, I tried to conduct interviews in an open ended style, to allow the possibility of pursuing areas of inquiry that were significant to the individual.

The choice of whom to interview just "happened" initially, but I became much more intentional as my time in Hearts \& Hands progressed. The Deputy CFO provided me with a letter of introduction, which I presented to each person I approached when requesting an interview. At Head office, this was not difficult, as I was in the same building as my "subjects". People were usually happy to book a time ahead, and I began to get into a pattern of conducting three or four interviews a day, allowing time in between to write diary notes after each meeting.

When interviewing people in the outlying areas, my initial contacts were by telephone or letter, and the organization and coordination of interviews became a much more time-consuming and challenging task. I refined the process of making contact, booking interview times, and confirming appointments. Armed with a list of personnel and their locations, and a street directory, I usually made contact, initially, by telephone. If anybody displayed the slightest hesitation in wanting to talk with me, I immediately suggested sending the CFO's letter of introduction, together with material that explained what I was undertaking. In most cases, when I followed this with a telephone call, people were willing to talk, and all that remained was setting a mutually convenient time. After one negative experience of making an initial contact by telephone, I changed to sending letters in the first instance, and this strategy worked well when followed up with a telephone call. One reason people gave for feeling apprehensive about an interview was that they did not know much about finances. I usually explained that the purpose of the interview was not to find out how much they knew, but rather, how they responded to financial matters within Hearts \& Hands.

The issue of choosing people to interview, and how many interviews to conduct, was a constant challenge. My initially serendipitous approach at Head Office quickly changed as I tried to cover ordained and non-ordained staff, men and 
women, church members and non-church members, and to include a variety of hierarchical ranks. It became obvious that Head Office ordained staff and employees had a particular viewpoint that was not always shared by others outside Head Office. With eight separate areas, I knew it would be impossible to saturate each one, so I chose Central Area as my primary area of interest, but conducted a few interviews also in other areas.

Apart from technical matters, interviews can also be thought of in terms of their ethical considerations, such as anonymity and the issue of intrusion into the participant's thoughts, observations and beliefs. Since the "objects of inquiry" are human beings, extreme care must be taken to avoid harming them, and to ensure that their right to privacy is respected (Fontana and Frey, 1994, p. 372). While the possibility exists that interviews may cause distress, this can be minimised by ethical conduct on the part of the interviewer as well as the participant's ability to have "considerable control" over the interview process (Corbin and Morse, 2003, p. 335). Especially if the material is sensitive, people who agree to be interviewed may be risking a great deal by speaking about their situation, and the researcher must go to considerable lengths to establish trust, protect identities, and maintain the confidentiality that has been agreed upon (Irvine, 2003).

Confidentiality had been a serious issue from the time of negotiating access, particularly in the conduct of interviews. As arranged, I recorded all interviews, and took great care to store tapes and transcripts in a secure place, to send transcripts in envelopes marked "confidential", and never to disclose the content of an interview to anybody else. My consciousness of the need for confidentiality grew stronger as I conducted more interviews. It became clear to me that people were taking a risk in talking to me, at least in their view. They needed constant reassurance that what they shared with me would remain confidential. Sometimes they would pause in the middle of the interview, ask me to stop the tape, and again require assurance that their identity would not be revealed. I developed five stages at which I assured interviewees of confidentiality: in the initial letter, when confirming the appointment by letter, at the beginning of the interview, when I sent the transcript to be read and signed, and if I had to send a reminder to ask people to return the signed transcript to me. In spite of this information being included in another letter, this part of the process caused some anguish for a few people. Several contacted me in some agitation, asking for further assurance that their identity would not be revealed. 
A third way of considering an interview is as a "linguistic event unfolding in particular sociopolitical contexts" (Schwandt, 1997, pp. 74 - 75). This is the dynamic that it is not so easy to define or specify, the search for a "holistic understanding" of the situation from the point of view of the person being interviewed (Tierney, 1991, p. 9). Technical aspects can contribute towards this, but ultimately, it may be that it is dependent on the quality of the interview itself, which may be difficult to control.

Transcripts of interviews do not always make plain what the context of an interview is, and in that sense, a transcript can never replace an actual event. If interviews are to be put to "honest and intelligent use in theorizing about social life", they must be understood as not merely collections of words which express an opinion, but, more than that, as stories produced in a particular setting at a particular time (Miller and Glassner, 1997, p. 111). A diary of the setting of each interview, including physical location, the apparent mood of the person being interviewed, any special problems or items of significance surrounding the interview, body language, or other significant factors will assist in the writing up process, to capture the situation and thoughts of the person being interviewed, so that the reader can share the understandings the researcher has arrived at.

Interviews produce more than data. Researchers speak of the "exhilaration" of conducting interviews, and of the excitement of meeting new people, and of coming "to understand some they thought they might not want to meet" (Glesne and Peshkin, 1992, p. 91).

A day spent traveling, conducting five or six interviews, and taking notes, was an exhausting day. But the thrill of making contact, of understanding somebody else's situation, of seeing things through their eyes, was enlightening. At the same time, I had to acknowledge that I had only stepped into their world for a short time, and 
only to the extent to which they granted me admittance.

\section{Observation and conversation.}

In conducting interviews, it is an advantage to be a participant observer first, in order to assist with the challenge of creating useful questions, "ones whose answers provide you with pictures of the unseen, expand your understanding, offer insight, and upset any well-entrenched ignorance" (Glesne and Peshkin, 1992, p. 67). Participant observation involves the collection of data in a "natural" or "field" setting (Walizer and Wienir, 1978, p. 333). In seeking to answer the question "what's going on here?", "direct firsthand eye-witness accounts of everyday social action" are regarded as vital (Schwandt, 1997, p. 106), since "observational data, especially participant observation, permits the evaluation researcher to understand a program or treatment to an extent not entirely possible using only the insights of others obtained through interviews" (Patton, 2002, p. 25).

Data of this type are valuable for a number of reasons. It means that a different perspective of the people being studied is understood, apart from the public performance they give; great attention can be paid to details, such as interactions, events, personalities and relationships; the social and historical context in which events and actions occur can be explained and understood; and the ongoing nature of personal relationships and behaviour can be grasped, being revealed not only as a set of separate events, but as a continuing saga of organizational life (Schwandt, 1997, p. 106).

If the degree of participation/observation is taken as being on a continuum, with observation on one end, and full participation on the other, the researcher 
positions himself or herself somewhere on that line, depending on the theoretical viewpoint of what constitute the goals of the participant-observer. The image of a white-coated laboratory scientist observing people behind a one-way mirror, and jotting down notes on a clipboard, is a "detached and sterile" view rooted in "the quantitative observational paradigm" (Adler and Adler, 1994, p. 378). It bears no similarity to ethnographic practice.

In the conduct of ethnography, it would be unrealistic to suggest that the presence of an observer does not affect the dynamics of organizational behaviour. However, the more frequently the observer is present, and the more taken-forgranted it is to have that person there, the more likely it would seem that organizational members would behave in their normal way. If the goal is to visit backstage, to achieve an understanding of the research setting, the people being studied, and the way they behave (Glesne and Peshkin, 1992, p. 42), then participation may be something that occurs as part of that process, upon invitation, or upon being included in the workings or even the decision making of the group.

Like the pebble thrown into the pool, which causes ripples right out to the boundaries of that pool, the observer dives into organizational life, and affects it in unanticipated ways. People are met, meetings are attended, interviews are arranged, opinions are sought, events are observed, friendships are formed, alliances are cemented, cases are presented, and lobbying takes place. The very presence of the researcher in the everyday settings of organizational life means that mere observation is impossible. Participation will occur, even if it is unconscious on the part of the researcher. Balancing the costs and benefits of participation, while desirable, may not be an option, as certain activities will 
simply occur, perhaps unexpectedly, throwing the researcher into a theoretical spin. While in a sense the researcher stays at the margins of the organization, there may be times when he or she is very much in the centre of the action (Glesne and Peshkin, 1992, p. 58).

My initial belief, that I was an observer at Hearts \& Hands, began to change within a short time of my arrival in the Accounting Department. I could not hold myself aloof from what was going on, and what is more, I did not wish to. Even before I began conducting interviews or attending meetings, people initiated conversations with me, giving me their point of view about what was going on, and what they felt needed to happen. In my näivete, at first I accepted these opinions on face value, but later realized I was probably being lobbied. Some people, knowing that I was to write a report, sought my opinion and approval, used me as a sounding board to put forward their action plans, or saw me as a potential ally. In a system that included ordained and non-ordained employees, there were frustrations within both groups. Trained professionals were often scathing of the lack of expertise of ordained staff, who were often above them in the organizational hierarchy. Ordained staff, in their turn, expressed concern that the organization ought not to be taken over by employees, who did not fully hold to Hearts \& Hands' mission. On a few occasions there were dramatic moves, or strong disagreements that left people upset or alienated, and they were eager to have a listening ear. On many occasions, I had to hide what I knew about people, because information had been given to me in confidence.

The conduct of fieldwork can be exhausting and anxiety-producing. In fact, anxiety has been described as "a research companion", manifest in the "mental and physical fatigue from overdoing" (Glesne and Peshkin, 1992, p. 56). The tension of remaining on one's mental toes always, of being ready to grasp new opportunities, of battling to understand what is going on, of exercising self control in the face of disappointment and discovery, and of leaving the field at the end, make the conduct of fieldwork like an emotional rollercoaster.

\section{Fieldnotes.}

Fieldnotes are a vital data source for the ethnographer. What they are exactly is open to debate, but they could be thought to include raw data or material such as notes, diagrams, or charts, field journals and everything else gathered in the 
course of fieldwork, such as documents, transcripts, and journals (Schwandt, 1997, p. 52). Prepared by an individual, they are therefore very much dependent on that individual's style and personality. Field observations are a reflection of the observer's "cognitive idiosyncracies", i.e. his or her thoughts and theories (Kirk and Miller, 1986, p. 51). Apart from the technical aspects of recording and classifying notes, what the researcher believes is worth recording depends on his or her understanding and beliefs, and existing knowledge of the organization or situation (Wolfinger, 2002).

From the beginning my diary was a reflective document, including my observations, opinions and theories. The act of formulating these thoughts helped me to make sense of what I had observed. I recorded details of telephone conversations, letters written and received, and interviews I conducted. The development of theory can be traced through my diaries, as well as the highs and lows of fieldwork.

\section{Documents.}

Even though ethnographic fieldwork was originally conceived as being for research in non-literate societies, in modern western society documentation is part of "the fabric of everyday social life" (Atkinson and Coffey, 1997, p. 45). Paperwork, in the form of annual reports, financial accounts, minutes of meetings, and other documents, cannot be ignored. In fact, so reliant is our society on this sort of documentation, that to ignore it would be to distort the context in which organizational behaviour occurred. And yet they are not spontaneous, uncontrived representations of organizational action:

They construct particular kinds of representations with their own conventions. We should not use documentary sources as surrogates for other kinds of data. We cannot, for instance, learn through records alone how an organization actually operates day-to-day. Equally, we cannot treat records - however 'official' - as firm evidence of what they report (Atkinson and Coffey, 1997, p. 47). 
Once words are put into text form, the gap between the "author" and the "reader" widens, and difficulties of interpretation occur (Hodder, 1994, p. 394). Words and their meanings can be changed when written down, because written text is an artifact, "capable of transmission, manipulation, and alteration, used and discarded, reused and recycled" (Hodder, 1994, p. 394). Taken out of context, documents can take on a meaning or interpretation that was not originally intended. They can conceal or disguise events, sanitize meetings and decisions, or even manipulate records of what actually occurred. They often enshrine "a distinctively documentary version of social reality", with their own conventions (Atkinson and Coffey, 1997, p. 47).

Documents construct a particular view of reality, sometimes designed to put forward a case, justify a position, or present an image. They are often anonymous, which possibly gives them a greater authority or perception as a factual account, than if they were attributed to a particular author. Readers may need to be expert in order to interpret them, or to understand the context in which they were written, but of course, there is not a great likelihood this will be the case. Once the words have been committed to paper, they are enshrined as an objective, official account (Atkinson and Coffey, 1997, pp. 59 - 60). Time stands still, and events are decontextualized, with the written record taking precedence over people's own recollections of activities and events (Atkinson and Coffey, 1997, p. 56). Documents are produced for a particular audience, with a particular viewpoint in mind.

Some of the documents I studied included Budget Committee minutes, Annual Books, letters, written instructions about budget procedures, consultants' reports, Personnel Placement manuals, Annual Financial Reports, and internal memos and reports. 
It was interesting to note the way in which the written word became enshrined in fact and history. The mission statements that were displayed in pride of place in many departments provided a good example of this. Few people questioned them, and with a few notable exceptions, there seemed little concern about developing strategies in order to achieve them. The minutes of meetings provided another example of the power of the written word. The "official" minutes of Budget Committee meetings, in comparison with my own "full" notes, were very economical in their use of words, reducing what had often been fascinating and topical discussions to the simple record of the passing of a particular motion. The Accountant informed me that at one meeting I missed, the Budget Committee members, frustrated at the unwieldy nature of the budgeting process, had had an in-depth discussion about what the role of the Committee ought to be, and what was its purpose for existence. Eagerly, I obtained a copy of the minutes, only to find that there was no record of the discussion at all. Had I not heard of it from somebody who was there, I would never have been aware that it had taken place. From the standpoint of the official minutes, it is as though the discussion had not taken place at all. Having observed this, my viewpoint of minutes from previous years changed, and I found them to be of lesser value than I had previously believed. Perhaps the numbers were accurate, but the tenor of what went on, the opinions, and the disagreements, were missing. The official record had been sanitized.

The fascination of documents for an ethnographer is attempting to gauge the effect they have on organizational members, or the disparity between those records and organizational reality, as it exists. Once committed to written form, words were there to stand forever, taken at face value, and not read as a testimony to another time and place, and another context. Taken out of context, and read by an audience different from the one intended, they had a very different effect from the one they were initially intended to have.

\section{How theory fits in.}

One of the most significant areas in which various accounting case studies differ is in the way they incorporate theory. The role of theory in case studies is by no means clear and unambiguous (Llewelyn, 2003), depending on the researcher's view of what constitutes inquiry, and the relationship between theory and data. Humphrey and Scapens (1996, pp. 98 - 100) suggested that theories are "rhetorical devices for both interpreting case studies and convincing the research community as to the validity of the case findings and interpretations", and advocated the use of multiple theories. It is not until the theoretical frameworks of researchers engage with the "pre-understandings of the researched community" that a 
hermeneutic circle would be formed, i.e. that accounting theories would display "practical adequacy in the world" (Llewellyn, 1996, p. 115).

Llewellyn (2003, p. 699) identified five different ways of theorizing as metaphor, differentiation, conceptualisation, context-bound theorizing of settings and context-free "grand" theorizing, and suggested that the first four had been underemphasized in qualitative management and accounting research, while "grand" theorizing had been over-emphasized (Llewellyn, 2003, pp. $663-4)$.

This view emphasizes the need for a stronger relationship between the development of theory and the data observed in the course of fieldwork. Jönsson (1998, p. 411) expressed similar ideas, suggesting that management accounting research had been "out of focus", with much empirical work producing failing to link empirics and theories. Advocating an ethnomethodological approach, his aim was to focus on social phenomena, and to link management accounting studies more closely with actual managerial work, particularly by studying the way participants communicated through conversation.

The need for flexibility and a high tolerance for ambiguity on the part of a qualitative researcher, already mentioned, are especially relevant in the area of theory development or application. Whether a qualitative research project is undertaken as a vehicle for demonstrating a theory (Lowe, 2001, p. 347), or whether a theory is adopted or developed as an interpretative response to the data gathered, the construction of theory will be informed by what has been observed, not merely by studying what books say about it:

What constituted the initial 'reflexive turn' in academic theorizing resulted from a heightened self-awareness associated with the increasing realization that the researcher/theorist plays an active 
role in constructing the very reality he/she is attempting to investigate (Chia, 1996, p. 42).

The notion that theory both informs observation, and is developed by it, is a wellestablished concept within the field of ethnography (Humphrey and Scapens, 1996, p. 100).

The framing of an institutional theory interpretation in my study of Hearts \& Hands came about through a reflexive relationship between theory and my interpretations of the way the organization operated. It became obvious to me that the budget was both the product of the distinctive culture and setting of Hearts \& Hands, and at the same time, the cause of certain effects within the organization. As I continued my research, I investigated various theories that might explain the way the organization functioned. None of them really seemed to offer the explanation I was looking for until I "discovered" institutional theory. Hearts \& Hands was, to a large extent, institutionalized. It had adopted procedures and practices in response to pressures not only from without (the environment) but from within (its own history and culture), and these had become enshrined and entrenched in organizational behaviour and structure. As I gained a greater understanding of institutional theory, I realized that while this was the case, there was also another factor present within Hearts \& Hands' workings, and that was the pro-active strategies they developed in order to raise funds to continue their operations. In this they were innovative and pragmatic. This observation led to the integration of certain aspects of resource dependence theory, as my theoretical structure began to take shape.

Within qualitative research, there can be said to be a "collection of assumptions, methods, and kinds of data that share some broad family resemblances" (Atkinson, 1995, p. 120), but with significant differences. Because of these different inquiry paradigms, case studies can span a wide range of ontological, epistemological and methodological beliefs (Heron and Reason, 1997, p. 284), which, whether acknowledged or not (May, 1994, p. 19), are present in any research undertaking:

The superficial attraction of our empirical research was the promise that a secure grasp of empirical reality would release us from the bonds of competing ideologies. In practice, however, we brought our own assumptions and beliefs to the work (Roberts and Scapens, 1990, p. 107).

When I began this research project, I had my own preconceived notions, which 
were challenged in the course of the interviews I conducted. Subconsciously, I had a positivist view about the way an organization "ought" to function. Almost ruthlessly, after analyzing the mission statement of Hearts \& Hands, I asked people whether they thought the organization had been successful at achieving its mission. Time and again, in spite of the fact that Hearts \& Hands had not increased its membership base in Australia since World War I, the response I received was a definite yes! I began to realize that this belief required a different definition of "success" from the "objective", irrefutable one I had in my mind. The very fact that Hearts \& Hands had survived, that its influence had grown, that it had established itself as almost an icon in Australian society, contributed towards this image of success. The perception of its success had nothing to do with the size of its membership base, or with how efficiently or effectively it functioned, but with its image and the fact it had survived.

A trap in qualitative research is to treat theory as fact. Theory is created as nothing more than a "best guess" (Morse, 1994b, p. 32), an interpretation or explanation of human behaviour. Theory provides structure to qualitative data, maturing throughout the research process:

If one ever finishes, the final "solution" is the theory that provides the best comprehensive, coherent, and simplest model for linking diverse and unrelated facts in a useful, pragmatic way (Morse, 1994b, p. 32).

It would be tempting to close in on a theory too early during a qualitative research project. By the time I became aware that institutional theory could be relevant to Hearts \& Hands, I had a sizeable store of data that I had absorbed, and which made it relatively easy to assess the applicability of that theory. Earlier in the process, I would not have had the same grasp of the organization. My awareness that institutional theory was an appropriate means of explaining the phenomena I was observing emerged through the research process as I collected, sifted, sorted and analyzed data. I refined institutional theory so it would become a better description of my data. Figure 1 below, "The process of developing theory", illustrates how the data and my understanding of theory both "informed" my perceptions and understandings of what was actually going on in Hearts \& Hands.

\section{(Take in Figure 1)}

\section{Data analysis.}

What does the qualitative researcher do with the large amounts of data he or she gathers? To some researchers, the term "analysis" seems inappropriate in relation to qualitative data, but whatever the level of complexity in the process of analysis, 
there will some analysis conducted, even if it is simply in the way information is filed, stored or sorted. The "richness and complexity" of the data compound the difficulty of interpretation and analysis (Roberts and Scapens, 1990, p. 107), but while initially the data may seem confusing, analysis begins as soon as the researcher begins collecting data (Shaw, 1999, p. 64). Data analysis conducted simultaneously with data collection, and with theory development, helps the qualitative researcher to understand and shape the study as it continues. This can be accomplished by means of a reflective log or diary, the filing of data by categories, simple coding schemes, monthly reports, the maintenance of some sort of control over the data in terms of organization, refinement of a coding system as the study becomes more focused, and the display of data by means of visual representations such as diagrams, spreadsheets or flowcharts (Glesne and Peshkin, 1992, pp. 128 - 137).

I never felt totally in control of the data I had collected at Hearts \& Hands. As the pile of memos, board meeting minutes, letters, reports, year book figures, interview transcripts, and diaries mounted, it was a challenge to devise an adequate sorting system, to assist in making sense of what I was collecting. It was not until I began uncovering information that I could ascribe categories to it, organize it, and reflect upon it. The analysis process continued as categories of information developed in my thinking. After a time the process became easier, and I began to find that when I absorbed some new piece of data, I had a mental (and physical) place ready in which it could be stored.

The organization, selection, interpretation and presentation of data are used to build a "theoretical rendition of reality" (Strauss and Corbin, 1990, pp. 21 - 22). Times of enlightenment or clear-thinking for the researcher can be hastened by adopting a stance of active inquiry, making frequent and full notes, and keeping theoretical literature separate from the data (Morse, 1994b, pp. 28 - 29), but even then, the researcher can fail to make connections because of underlying assumptions, experience, and theoretical expectations (Strauss and Corbin, 1990, 
p. 75). It is a delicate balance, keeping alive and useful the tension between understanding and absorbing the data, and allowing theoretical aspects to both inform and be informed by the process of data collection and analysis.

Whatever else it is, qualitative data analysis is not a "passive endeavour", but requires comprehension, synthesizing, theorizing, and recontextualizing [23], by means of "astute questioning, a relentless search for answers, active observation, and accurate recall" (Morse, 1994b, pp. 25 - 34). Sometimes acknowledged as the most important part of ethnography, the development of generalizations is not always held to be a necessary part of the process, with opinions on the generalizability of theory derived from qualitative research varying greatly (Schwandt, 1997, pp. 57 - 59; Lukka and Kasanen, 1995, p. 73; Ragin, 1994, p. 91). However far this process of analysis is carried, it is undeniably a cognitive struggle, which needs to be made explicit, and which, if it is described, will dispel the notion that qualitative research is "easy" (Morse, 1994b, p. 24).

For me, describing what happened was not satisfying enough. I had to know why, or at least to have a plausible explanation of why things occurred. And yet nobody ever explained how much hard work and anxiety went into the process of data collection, study, and analysis before "things suddenly became clear" or " a pattern began to emerge". Even at the earliest stage of the research process, I attempted, hesitatingly, to analyse the data I collected. Perhaps the most significant organizing factor which "emerged", was that the budgeting system was deeply embedded within the organizational culture, that there were organizational structures and practices which had a profound impact on attitudes to money and fundraising, and, by extension, to the budgeting process. A further constraint, or category, was the expertise of the personnel involved in the process. This, in its turn, overlapped with the distinctive organizational culture, and the ordained/employee tensions I had observed. Developing these categories was the hard work of dealing with data. It was only as this "happened", that the physical aspects of data storage could be developed in a way that was meaningful and useful. 
The collection, organization and interpretation of data constitute analysis. There is no standardized procedure for data analysis within qualitative research, but rather a "fluid" process of making sense of data (Tesch, 1990, p. 4).

Just as organizations differ, so do researchers. Some like having everything set down and planned well in advance. I preferred a serendipitous approach, within broad guidelines, and while this worked well, it meant my tolerance for ambiguity had to remain high for a long time. Towards the end of the access period, I was almost desperately seeking closure on my method of data analysis, and my understanding and development of theory.

Faced with a huge amount of data, the qualitative researcher has the challenge of sorting and arranging the data without losing its richness. How can this be sorted, in a physical sense, into categories? Colour-coded folders, a file-card system, or electronic data handling are several options (Tesch, 1990, pp. 128 - 134). Folders and file-cards could be unwieldy, but is it a contradiction of terms to analyze qualitative data by means of a computer programme? Many researchers would suggest that it is not (Walker, 1993; Tesch, 1990; Parker and Roffey, 1997; Glesne and Peshkin, 1992; Singh, 1997). From the use of word processors, and databases, to qualitative analysis programmes, there is a large range of software that can assist the data analysis process.

The NUD*IST (Non-numerical Unstructured Data Indexing, Searching and Theorizing) computer programme (QSR NUD*IST 4, 1997) is a qualitative data analysis programme that "streamlines text analysis and searches for patterns and meanings which generate a parsimonious theory" (Parker and Roffey, 1997, p. 237). Singh (1997, pp. 40 - 41) observed that the use of NUD*IST for her analysis of data on marriage money helped reveal some of her initial biases, kept track of how the analysis of her data was being shaped, and was central in the transformation of data to theory. Such analysis, whether it involves the process of 
entering data into a database or less "technical" analysis, serves two related purposes: to make the researcher totally familiar (again) with the data, and to help in "structuring and organizing data into meaningful units" (Shaw, 1999, p. 65).

With 104 transcribed interviews, as well as a huge volume of other paperwork, the difficulty of searching for information would have been haphazard without a qualitative database. I therefore embarked on an investigative journey to discover whether there was a software package that would suit me. My investigations led me to NUD*IST. The beauty of the program was that it could be changed as my theory developed and the focus of my research issues changed, and added rigour to my analysis.

\section{Getting out.}

\section{Fulfilling all the requirements.}

The most demanding and time-consuming requirement of the access arrangement was that of transcribing all interviews. Along with the transcribing itself, there were many associated administrative tasks, set against the backdrop of the confidentiality arrangements that had been agreed upon. The final report was a huge anti-climax, written in the context of difficulty in communicating with the new CFO. During my year of access, most of the top hierarchy moved. The Deputy CFO and the CFO had both been replaced by the time I presented my report, as had the overall head of the division. Changes like this were a consistent pattern at Hearts \& Hands, and in this instance, meant that the report was now being compiled for an audience of one, the new CFO. The discussion that had been the aim of the former CFO now did not eventuate.

\section{Signing off.}

Leaving the research site can be a "bittersweet time" (Glesne and Peshkin, 1992, p. 60), when feelings of relief at finishing the exhausting process, and sadness at leaving the people and the action behind, are juxtaposed.

My access time at Hearts \& Hands did not end exactly as I would have wished. During the year, most of the top hierarchy to whom I was to report were transferred out of the division, and the new personnel were not as interested in my work. Not only was I now not required to present a report to the executive staff, but there were also some unresolved issues about the use of the organization's name. After my numerous failed attempts at discussion of this issue with the new $C F O$, it was finally agreed that the name could be used, but not in the title or the abstract of my thesis. I experienced a sense of dissatisfaction. It had been an extremely busy yet productive year, yet I left with a vague sense of disappointment 
that while most of the relationships I had formed there had been happy and fruitful, there were one or two that had simply not worked.

\section{Constructing a reliable and interesting ethnographic text.}

The construction of a convincing research text from a "mountain" of data, field notes, diary entries, meeting minutes, interviews and reports is a mammoth task (Ryan et al, 2002, p. 157). Writers about organizations need to acknowledge that their own accounts are, first and foremost, "linguistic constructions which operate according to established conventional linguistic codes" (Chia, 1996, p. 45). Ethnographic narratives can therefore be "powerful tools" for opening up new areas of inquiry, if they achieve the goal of being representative, interpretive and rhetorical (Jönsson and Macintosh, 1997, p. 370, p. 385). They are representative in that they tell the stories of people in a particular culture, and provide the context in which those people live and act. They are interpretive because they attempt to "set forth categories, make comparisons, and interpret symbols and rituals", and they are rhetorical because they attempt "to bring the distinctive social world into some sort of textual order that not only pleases the reader but, more importantly, produces a concrete, sharp, and complex portrait of life in the community, one that persuades the reader that the narrative can be trusted" (Jönsson and Macintosh, 1997, p. 370).

My purpose in composing the story of Hearts and Hands, as I saw it, was not to produce an expose of the autocratic structures and political dynamics of the organization. That there were problems was undeniable, but in my opinion they were not of a nature that demanded public revelation. Rather, my respect for various organizational members grew as I observed the way they wrestled with some of their own challenges and inconsistencies. It was important that the writing of an ethnographic account would be true to the organization as I observed and interpreted it. The challenge was to choose which data I would use, and to put it together in a way that was both interesting and engaging, to produce a unique "product". The sifting process, which began at the conception of the project, now continued. Without doubt, another researcher would produce a 


\section{different story.}

The extent to which an ethnographic narrative can be trusted is an issue of reliability and validity, not just at a practical level, but at a theoretical level as well. To some extent, because of the categorisation of data and the use of theory, the ethnographer can be said to be "artfully creating a text" (Watson, 1995, p. 302). And yet, from the other end of the spectrum (the recording of a "scientific" set of facts), by including in a description of the setting, a narration of the stories of individuals, actual dialogue, the privileging of objects of inquiry, and the recording by the writer of his or her own involvement in and response to the researched situation, an ethnography transcends a "scientific monograph".

The writer of an ethnographic study instead invites the reader to come on an "exciting search", couched in rhetoric, in the "ancient sense of persuasive discourse" (Watson, 1995, p. 305, p. 307). As ethnography has moved away from its traditional roots, requiring validity and objectivity (Denzin, 1996, p. 233), and has entered the terrain of fictional writers, the line between fact and fiction has sometimes been blurred, and the issues of reliability and validity, and generalizability, have become problematic.

By taking into account the reflexive relationship between theory and data, and between researcher and researched, claims to accuracy are not as important, but the ethnographic product can be thought of as an interesting story, rather than a "privileged truth claim". The aim is that it ought to be an "intelligible narrative" rather than a systematic attempt "accurately to describe and explain an external organizational reality" (Chia, 1996, p. 33). Where once knowledge was said to rest on "unambiguous observations", theoretical concepts could now be viewed as growing out of the "soil" of observation. 
Coming into Hearts \& Hands as an outsider gave me the opportunity to have a bird's eye view that insiders would not have. As I conducted more and more interviews, developed my theoretical structure, and reflected on what I had observed, I became more and more confident in my interpretation of events and behaviours as I understood them. Not bound up in Hearts \& Hands' unique history and culture, I yet came to appreciate it as an almost tangible force, both empowering and constraining behaviour, especially on the part of ordained staff members. I was aware that many of my interpretations found agreement with various people I spoke with.

With these criteria in mind, qualitative researchers often display an "unwillingness to generalize" (Ragin, 1994, p. 91). The act of reasoning "from the observed to the unobserved, from a specific instance to all instances believed to be like the instance in question" is traditionally held to be one of the criteria for "social scientific inquiry" (Schwandt, 1997, p. 57). Several different positions on generalizations can be identified (Schwandt, 1997; Lukka and Kasanen, 1995), ranging from the radical postmodern view which denies the possibility of generalization, to the notion that "substantial results of a case study also hold true for other cases" (Lukka and Kasanen, 1995, p. 77).

The meaningful mobilization of the results of research is thus a problematic concept, since the failure to provide each one of the three qualities of simplicity, generality and accuracy is "inevitable and no cause for criticism" (Chapman, 1997, p. 190). The recognition of this has implications for the use that is made of ethnographic work. Given that the individual situation is different and distinct, the issue is whether the principles, or underlying theory, may be applicable to other situations. There is no such thing as a completely objective piece of research (Kirk and Miller, 1986, p. 11; Glesne and Peshkin, 1992, p. 101; Douglas, 1985, p. 42), and therefore the "validity" of a piece of research is more a matter of whether it is a reasonable account of what has been observed. 


\section{Conclusion.}

This has been a first-hand account of a qualitative research project, focusing not on the data itself, except obliquely, but on the way in which the project was conducted. Its purpose has been to fill a gap within academic accounting literature about how qualitative research projects are actually conducted. Qualitative research, particularly ethnography, is a rich and exciting, but sometimes frustrating and exhausting, means by which to attempt to understand what is going on in the worlds of other people. I am grateful to Hearts \& Hands for allowing me access, and hope that the account I prepared does justice to what actually goes on. That particular account is not presented in this paper, but the issues relating to its construction have been. Have I made an interpretation of the data I have collected in a way that faithfully reflects the experience and behaviour of those within the organization? Have I produced an engaging and interesting account? Is it a believable and convincing account? Is the theory relevant to practice as I have observed it? Those are the issues against which my account will be judged. The ethnographer issues the invitation: come with me into another world. Enter Hearts \& Hands (or some other organization) with me, come behind the scenes, backstage, to see and attempt to make sense of what actually goes on.

The invitation of this paper has not been to enter Hearts and Hands, but to go backstage in the conduct of the research study. While the level of information provided about the case may produce frustration in some readers, it has been intentionally structured in that way, as a reverse of the practice in most qualitative accounting studies, where the case is produced with little or no information about the way in which it was conducted. That also leads to a different kind of frustration on the part of other qualitative researchers, the frustration of not discovering enough about how it happened, what went wrong, what the issues were that the researcher grappled with, who were the difficult people to deal with, how access was arranged, and a multitude of other hidden information. Researchers not involved in qualitative research may imagine, by reading some accounts, that qualitative research is predictable and trouble-free. This has been shown to be far from the usual experience of a qualitative researcher.

This paper is thus both theoretical and reflective, and is unashamedly about qualitative research from the point of view of a researcher, rather than a 
qualitative research paper about an organization. It addresses the silence, within qualitative research in accounting, about the way in which that research has been undertaken. Because the focus is personal rather than organizational, it does not offer "findings" about the way in which accounting is practised, but rather reflections and insights about the way the research was conducted, from getting into the organization, conducting the research and finally making an exit.

Even though this paper represents the reflections of one researcher conducting a qualitative study in one unique organization, there are lessons to be learned about the need for flexibility, reflection and reflexivity in qualitative research. While the intention of the authors is that this paper should be informative, it does not claim to be a manual of practice, but rather an account which both experienced and new qualitative researchers can read for confirmation or instruction about what the process of qualitative project is likely to look like.

\section{References.}

Adler, P. A. and P. Adler. (1994), Observational Techniques, in Denzin, N. K. and Lincoln, Y. S., Handbook of Qualitative Research, Sage Publications, Thousand Oaks, USA, pp. 377 - 392.

Altheide, D. L. and J. M. Johnson. (1994), Criteria for Assessing Interpretive Validity in Qualitative Research, in Denzin, N. K. and Lincoln, Y. S., Handbook of Qualitative Research, Sage Publications, Thousand Oaks, USA, pp. $485-499$.

Atkinson, P. (1995), "Some Perils of Paradigms", Qualitative Health Research, Vol. 5, No. 1, February, pp. 117 - 124.

Atkinson, P. and A. Coffey. (1997), Analysing Documentary Realities, in Silverman, D., Qualitative Research Theory, Method and Practice, Sage Publications, London, pp. $45-62$.

Atkinson, P. and M. Hammersley. (1994), Ethnography and Participant Observation, in Denzin, N. K. and Lincoln, Y. S., Handbook of Qualitative Research, Sage Publications, Thousand Oaks, USA, pp. $248-261$.

Baez, B. (2002), "Confidentiality in qualitative research: reflections on secrets, power and agency", Qualitative Research, Vol. 2, Issue 1, pp. 35 - 58. 
Baszanger, I. and N. Dodier. (1997), Ethnography: Relating the part to the Whole, in Silverman, D., Qualitative Research. Theory, Method and Practice, Sage Publications, London, pp. 8 - 23.

Boyle, J. S. (1994). Styles of Ethnography, in Morse, J. M., Critical Issues in Qualitative Research Methods, Sage Publications, Thousand Oaks, USA, pp. 159 - 185.

Chapman, C. S. (1997), "Reflections on a Contingent View of Accounting", Accounting, Organizations and Society, Vol. 22, No. 2, pp. 189 - 205.

Chia, R. (1996), "The Problem of Reflexivity in Organizational Research: Towards a Postmodern Science of Organization", Organization, Volume 3 (1), pp. 31 - 59.

Corbin, J. and Morse, J. M., (2003), "The unstructured interactive interview: issues of reciprocity and risks when dealing with sensitive topics", Qualitative Inquiry, Vol. 9, Issue 3, pp. 335 - 554.

Covaleski, M. A. and Dirsmith, M. W. (1990), "Dialectic Tension, Double Reflexivity and the Everyday Accounting Researcher: On Using Qualitative Methods", Accounting, Organizations and Society, Vol. 15, No. 6, pp. 543 - 573.

Darlington, Y. and Scott, D. (2002), Qualitative research in practice. Stories from the field, Allen \& Unwin, Crows Nest, New South Wales, Australia.

Dent, J. (1991), "Accounting and organizational cultures: a field study of the emergence of a new organizational reality", Accounting, Organizations and Society, Vol. 16, No. 8, pp. 705 - 732.

Denzin, N. K. (1996), “The Facts and Fictions of Qualitative Inquiry”, Qualitative Inquiry, Vol. 2, Number 2, June, pp. 230 - 241.

Denzin, N. K. and Lincoln, Y. S. (1994), Introduction. Entering the Field of Qualitative Research, in Denzin, N. K. and Lincoln, Y. S., Handbook of Qualitative Research, Sage Publications, Thousand Oaks, USA, pp. $1-17$.

Denzin, N. K. and Lincoln, Y. S. (1998), "Entering the Field of Qualitative Research", in Denzin, N. K. and Lincoln, Y. S. (eds), The Lancscape of Qualitative Research. Theories and Issues, Sage Publications, Thousand Oaks, USA.

Denzin, N. K. and Lincoln, Y. S. (2003), Introduction. The Discipline and Practice of Qualitative Research, in Denzin, N. K. and Lincoln, Y. S., The Landscape of Qualitative Research, Sage Publications, Thousand Oaks, USA, pp. 1 - 46.

Douglas, J. D. (1985), Creative Interviewing Volume 159 Sage Library of Social Research, Sage Publications, Inc., Beverly Hills, California.

Ezzamel, M., Willmott, H., Worthington, F. (2004), "Accounting and management-labour relations: the politics of production in the 'factory with a problem"”, Accounting, Organizations and Society, Vol. 29, pp. $269-302$. 
Feeney, S. (1997), "Shifting the Prism: Case Explications of Institutional Analysis in Nonprofit Organizations", Nonprofit and Voluntary Sector Quarterly, Vol. 26, No. 4, December, pp. 489 - 508.

Fine, M. and Weis, L. (1996), "Writing the 'Wrongs' of Fieldwork: Confronting Our Own Research/Writing Dilemmas in Urban Ethnographies", Qualitative Inquiry, Volume 2, Number 3, September, pp. 251 - 274.

Fontana, A. and Frey, J. H. (1994), Interviewing, the Art of Science, in Denzin, N. K. and Lincoln, Y. S., Handbook of Qualitative Research, Sage Publications, Thousand Oaks, USA, pp. 361 - 376.

Glesne, C. and Peshkin, A. (1992), Becoming Qualitative Researchers An Introduction, Longman, New York.

Heron, J. and Reason, P. (1997), “A Participatory Inquiry Paradigm”, Qualitative Inquiry, September, Volume 3, Number 3, pp. 274 - 294.

Hodder, I. (1994), The Interpretation of Documents and Material Culture, in Denzin, N. K. and Lincoln, Y. S., Handbook of Qualitative Research, Sage Publications, Thousand Oaks, USA, pp. 393 - 402.

Hopper, T. and Powell, A. (1985), "Making Sense of Research into the Organizational and Social Aspects of Management Accounting: A Review of its Underlying Assumptions (1)", Journal of Management Studies, Vol. 22, No. 5, pp. 429 - 465.

Humphrey, C. and Scapens, R. W. (1996), "Methodological themes, Theories and Case Studies of Organizational Accounting Practices: Limitation or Liberation?", Accounting, Auditing \& Accountability Journal, Vol. 9, No. 4, pp. 86 - 106.

Irvine, H. (2003), "Trust me! A personal account of confidentiality issues in an organizational research project", Accounting Forum, Vol. 27, No. 2, June, pp. $111-131$.

Jönsson, S. (1998), "Relate Management Accounting Research to Managerial Work", Accounting, Organizations and Society, Vol. 23, No. 4, pp. $411-434$.

Jönsson, S. and Macintosh, N. B. (1997), "Cats, Rats, and Ears: Making the Case for Ethnographic Accounting Research", Accounting, Organizations and Society, Vol. 22, No. 3/4, pp. 367 - 386.

Kirk, J. and Miller, M. L. (1986), Reliability and Validity in Qualitative Research. Qualitative Research Methods, Volume 1, Sage Publications, Beverly Hills, California.

Llewellyn, S. (1996), “Theories for Theorists or Theories for Practice? Liberating Academic Accounting Research?", Accounting, Auditing \& Accountability Journal, Vol. 9, No. 4, pp.112 - 118.

Llwewllyn, S. (2003), "What counts as 'theory' in qualitative management and accounting research? Introducing five levels of theorizing", Accounting, Auditing \& Accountability Journal, Vol. 16, No. 4, pp. $662-708$. 
Lowe, A. (2001), "After ANT An illustrative discussion of the implications for qualitative accounting case research", Accounting, Auditing \& Accountability Journal, Vol. 14, No. 3, pp. 327 - 351.

Lukka, K. and Kasanen, E. (1995), "The problem of generalizability: anecdotes and evidence in accounting research", Accounting, Auditing \& Accountability Journal, Vol. 8, No. 5, pp. 71 - 90.

Marshall, C., Lincoln, Y. S. and Austin, A. (1991), Integrating a qualitative and quantitative assessment of the quality of academic life: political and logistical issues, in Fetterman, D. M., Using Qualitative Methods in Institutional Research No. 72, Vol. XVIII, Number 4, Jossey-Bass, Inc., San Francisco, pp. $65-80$.

May, K. A. (1994), Abstract Knowing: The Case for Magic in Method, in Morse, J. M., Critical Issues in Qualitative Research Methods, Sage Publications, Thousand Oaks, USA, pp. $10-21$.

Miller, J. and Glassner, B. (1997), The 'Inside' and the 'Outside' Finding Realities in Interviews, in Denzin, N. K. and Lincoln, Y. S., Handbook of Qualitative Research, Sage Publications, Thousand Oaks, USA, pp. 99 - 112.

Morse, J. M. (1994a), “Qualitative Research: Fact or Fantasy?”, in Critical Issues in Qualitative Research Methods, edited by J. M. Morse, pp. 1 - 4, Sage Publications, Thousand Oaks, USA.

Morse, J. M. (1994b), Emerging From the Data: The Cognitive Processes of Analysis in Qualitative Inquiry, in Morse, J. M., Critical Issues in Qualitative Research Methods, Sage Publications, Thousand Oaks, USA, pp. $23-42$.

Mouck, T. (1998), "Neural Networks, Scaffolded Cognition and the Institutions of Financial Accounting", working paper prepared for presentation at the University of Wollongong Department of Accounting and Finance Tenth Annual Accounting Doctoral Consortium, July.

Muecke, M. A. (1994), On the Evaluation of Ethnographies, in Morse, J. M., Critical Issues in Qualitative Research Methods, Sage Publications, Thousand Oaks, USA, pp. 187 - 209.

Parker, L. and Roffey, B. H. (1997), "Methodological Themes: Back to the drawing board: revisiting grounded theory and the everyday accountant's and manager's reality", Accounting, Auditing \& Accountability Journal, Vol. 10, No. 2, pp. 212 - 247.

Patton, M. Q. (2002), Qualitative Evaluation and Research Methods, Second edition, Sage Publications, Newbury Park, USA.

Peräkylä, A. (1997), Reliability and Validity in Research based on Transcripts, in Silverman, D., Qualitative Research. Theory, Method and Practice, Sage Publications, London, UK, pp. $201-220$.

Preston, A. (1986), "Interactions and arrangements in the process of information", Accounting, Organizations and Society, Vol. 11, No. 6, pp. 521 - 540.

Punch, M. (1998), "Politics and Ethics in Qualitative Research", in Denzin, N. K. 
and Lincoln, Y. S. (eds), The Lancscape of Qualitative Research. Theories and Issues, Sage Publications, Thousand Oaks, USA.

QSR NUD*IST 4. (1997), Non-numerical Unstructured Data Indexing, Searching and Theorizing, Application Software Package, Qualitative Solutions and Research Pty. Ltd., Melbourne, Australia.

Ragin, C. C. (1994), Constructing Social Research. The Unity and Diversity of Method, Pine Forge Press, Thousand Oaks, USA.

Roberts, J. and R. Scapens. (1990), "Accounting as discipline", in Critical Accounts, edited by D. J. Cooper and T. M. Hopper, pp. 107 - 125, The Macmillan Press Ltd, UK.

Roulston, K., de Marrais, K. and Lewis, J. B. (2003), "Learning to interview in the social sciences", Qualitative Inquiry, Vol. 9, Issue 4, pp. 643 668.

Ryan, B., Scapens, R. W., Theobald, M. (2002), Research Method \& Methodology in Finance \& Accounting, $2^{\text {nd }}$ edition, Thomson, London, UK.

Sanday, P. R. (1979), "The Ethnographic Paradigm(s)", Administrative Science Quarterly, December, Volume 24, pp. 527 - 538.

Schwandt, T. A. (1997), Qualitative Inquiry, A Dictionary of Terms, Sage Publications, Thousand Oaks, USA.

Scott, W. R. (1965), Field Methods in the Study of Organizations, in March, J. G., Handbook of Organizations, Rand McNally College Publishing Company, Chicago, USA, pp. 261 - 304.

Shaw, E. (1999) "A guide to the qualitative research process: evidence from a small firm study", Qualitative Market Research, Vol. 2 No. 2, pp. 59 70 .

Singh, S. (1997), Marriage Money. The social shaping of money in marriage and banking, Allen \& Unwin, Sydney, Australia.

Strauss, A. and Corbin, J. (1990), Basics of Qualitative Research. Grounded Theory Procedures and Techniques, Sage Publications, Newbury Park, USA.

Tesch, R. (1990), Qualitative Research: Analysis Types and Software Tools. The Falmer Press, London, UK.

Tierney, W. G. (1991), Utilizing Ethnographic Interviews to Enhance Academic Decision Making, in Fetterman, D. M., Using Qualitative Methods in Institutional Research. New Directions for Institutional Research No. 72. Vol. XVIII. Number 4, Jossey-Bass Inc., San Francisco, USA, pp. 7 -21 .

Walizer, M. H. and Wienir, P. L. (1978), Research Methods and Analysis. Searching for Relationships, Harper \& Row, New York, USA.

Walker, L. (1993), "Computer Analysis of Qualitative Data: A Comparison of Three Packages", Qualitative Health Research, Vol. 3, No. 1, pp. 91 111. 
Watson, T. J. (1995), "Shaping the story: rhetoric, persuasion and creative writing in organisational ethnography", Studies in Cultures, Organisations and Societies, Vol. 1, pp. 301 - 311.

Weinholtz, D., B. Kacer and T. Rocklin. (1995), "Salvaging Quantitative Research with Qualitative Data", Qualitative Health Research, Vol. 5, No. 3, pp. 338 - 397.

Wolfinger, N. H. (2002), "On writing fieldnotes: collection strategies and background expectancies", Qualitative Research, Vol. 2, Issue 1, pp. $85-95$.

Young, J. and Preston, A. (1996), “Commentaries. Are Accounting Researchers Under the Tyranny of Single Theory Perspectives?", Accounting, Auditing \& Accountability Journal, Vol. 9, No. 4, pp. 107 - 111.

\section{Notes}

1. This is not just the case within accounting. Shaw (1999, p. 59) observed that in the field of small firm research, there was little attention given to the process by which qualitative research was conducted.

2. It has been suggested that field studies provide the input for quantitative studies by aiding in the development of hypotheses (Chapman, 1997, p. 203). It has also been proposed that quantitative projects produce results which can be "ambiguous and misleading" if they are not supplemented with qualitative data (Weinholtz et al, 1995, p. 388). Qualitative and quantitative research are not necessarily mutually exclusive, yet while they may seem complementary, underlying both of these research traditions are different philosophical assumptions about what constitutes reality and knowledge, and therefore what the purpose of inquiry is.

3. i.e. "doing qualitative field research, over merely talking about field research" (Covaleski and Dirsmith, 1990, p. 566).

4. The emergent nature of qualitative research means that it cannot be standardized, and the researcher must remain open to the possibility of developing and changing interpretations during the research process (Glesne and Peshkin, 1992, p. 6).

5. Many different types of ethnographies can be identified, including classical, systematic, interpretive and critical (Muecke, 1994, pp. 191 - 194), ethnohistorical, holistic, particularist, or cross-sectional.

6. This means not just the actual physical locality and environment in which people live and relate, but rather the complex circumstances behind those lives and relationships.

7. The ethnographic product is the descriptive and interpretive text that is produced as a result of the ethnographic process.

8 Hearts and Hands is a pseudonym.

9 Ryan et al (2002, pp. 143 - 145) identify five types of case studies: descriptive, illustrative, experimental, exploratory and explanatory.

10. In undertaking qualitative research, a researcher needs a question or questions that will give "flexibility and freedom to explore a phenomenon in depth" (Strauss and Corbin, 1990, p. 37). The flexibility is therefore in terms of setting the research agenda and developing theory, but it is also in the actual conduct of the research, since the "laboratory" of the qualitative researcher is everyday life, i.e., it cannot be "started, stopped, manipulated, or washed down the sink" (Morse, 1994a, p. 1).

11. Some reasons for conducting qualitative research include (Ragin, 1994, pp. 83 - 84): giving voice, i.e. representing groups which are not usually covered by other research approaches; interpreting the historical or cultural significance of practices or activities, i.e. to assist in the understanding of these aspects, which have sometimes been neglected in more traditional forms of research; and to advance theory, i.e. to develop, during the course of the research, concepts and ideas which are identified as significant.

12. Their willingness to participate, according to Scott (1965), depended on a number of factors, including their image, their confidence in their role and place in society, their history and culture, and their openness to ideas or to change. 
13 This is ethical in the best and widest sense of the word, i.e. not just in fulfillment of the demands of a university ethics committee.

14. Dent's longitudinal study of railway culture, for example, took place over a period of five years. Access was achieved through "various channels and contacts" (Dent, 1991, p. 711).

15. This is a pseudonym.

16. This caused problems later. They are detailed in "Signing off", later in this paper.

17. Qualitative research implies an emphasis on "processes and meanings that are not rigorously examined, or measured (if measured at all), in terms of quantity, amount, intensity, or frequency" (Denzin and Lincoln, 1994, p. 4). The personal inclination of the researcher has already been identified as a factor, in terms of the topic determined to be worthy of study, the underlying belief system that leads to such a determination, and the particular qualitative method which is chosen as a vehicle by which to pursue the research area of interest.

18. Dent's (1991) railway case study relied on data that included descriptions and accounts by the participants, and his own observations of activities and interactions, in their context. Unstructured interviews, meetings, and information gathered from casual conversations and simply "being around" (Dent, 1991, p. 711) over two years, with follow up visits, provided a rich source of data on which he based his analysis of the change in culture in a railway organization.

19. Preston (1986) initially intended studying a firm's computerized production information system. Over a period of a year, in which he gathered data by means of documents, interviews, informal talk, and observations, the focus shifted to the way managers kept themselves informed.

20. Nondirective or open-ended questions encourage spontaneity, and open up the possibility that those being interviewed can raise issues that they see as important (Tierney, 1991, p. 9), rather than being pre-determined by the researcher.

21. It is the assumptions underlying the research that determine which "tools" are most appropriate (Tierney, 1991, p. 9).

22. The potential problems of using a tape recorder when interviewing illustrate this observation. Both a "reassurance of the seriousness of your pursuit" and, at the same time, "a brutal technological reminder of human separateness that undermines the intimate communion you are trying to create" (Douglas, 1985, p. 83), the recorder should be handled with sensitivity, since it can be distracting for the person being interviewed.

23. Within ethnographic method, the process of comprehending occurs by means of observations, interviews, and the use of documents. Synthesizing involves the sifting of data as content is analyzed and categories are developed. The development of theory is the next step, the final "solution" being the theory that provides "the best comprehensive, coherent, and simplest model for linking diverse and unrelated facts in a useful, pragmatic way". Recontextualization is the process of developing theory-based generalizations that can be applied to other settings (Morse, 1994b, pp. 26 - 38). 


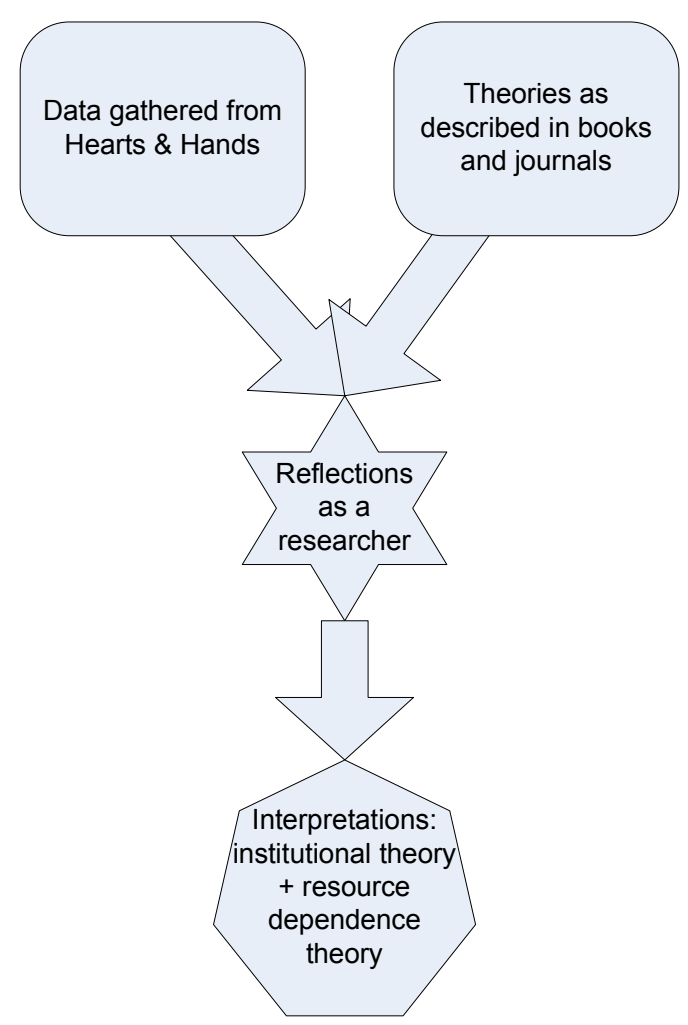

Figure 1. The process of developing theory. 